\title{
Ulcerated papules and nodules in an infant
}

\author{
José Miguel Neves $\mathrm{MD}^{1}$ (D) | Rita Ramos Pinheiro $\mathrm{MD}^{1}$ | Ana Isabel Cordeiro $\mathrm{MD}^{2}$ | \\ Alexandre João $M^{1}$ | Maria João Paiva Lopes MD, $\mathrm{PhD}^{1}$ \\ ${ }^{1}$ Department of Dermatology and Venereology, Hospital de Santo António dos Capuchos, Centro Hospitalar Universitário de Lisboa Central, Lisboa, Portugal \\ ${ }^{2}$ Primary Immunodeficiencies Unit, Hospital Dona Estefânia, Centro Hospitalar Universitário de Lisboa Central, Lisboa, Portugal
}

Correspondence: José Miguel Neves, MD, Department of Dermatology and Venereology, Hospital de Santo António dos Capuchos, Centro Hospitalar Universitário de Lisboa Central, Alameda de Santo António dos Capuchos, 1169-050 Lisboa, Portugal.

Email: josemoneves@gmail.com

A 15-month-old boy was admitted because of sudden onset of multiple painless papulonodular lesions of 2 weeks' duration. Past medical history was unremarkable. Physical examination revealed 12 erythematous, ulcerated papules and nodules, ranging from 1 to $5 \mathrm{~cm}$, some with a central necrotic crust located on the trunk, limbs, genital area, and the left upper eyelid (Figures 1 and 2). Persistent fever $\left(39^{\circ} \mathrm{C}\right)$ was noted without other relevant findings. Laboratory evaluation revealed severe microcytic anemia (hemoglobin: $7.4 \mathrm{~g} /$

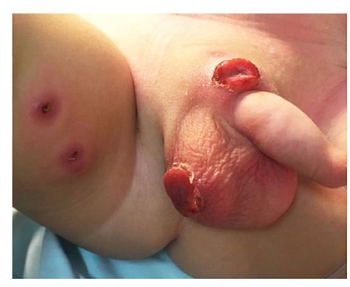

FIGURE 1

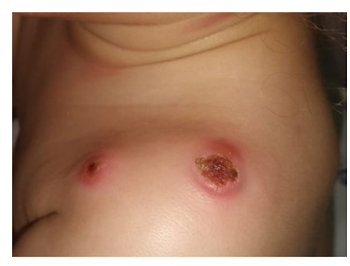

FIGURE 2

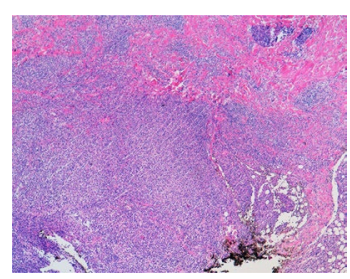

\section{FIGURE 2}

$\mathrm{dL}$; mean corpuscular volume: $53.3 \mathrm{fL}$ ) with elevated C-reactive protein $(87.6 \mathrm{mg} / \mathrm{dL})$ and erythrocyte sedimentation rate $(45 \mathrm{~mm} / \mathrm{h})$. No atypia was observed within the circulating blood cells. Cultures for bacteria, mycobacteria, and fungi were negative. Excisional skin biopsy of an abdominal nodule was performed (Figures 3 and 4).

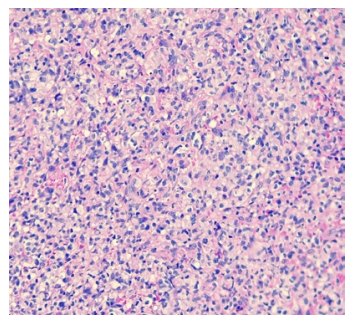

FIGURE 4

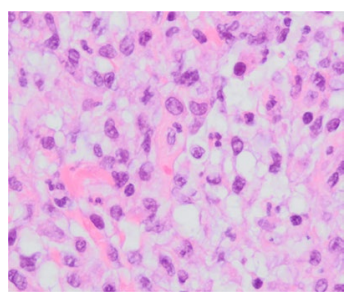

FIGURE 5

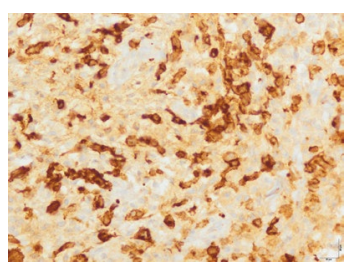

FIGURE 6 


\section{Diagnosis: Lymphomatoid papulosis}

The excisional biopsy specimen revealed a dense lymphoid dermal infiltrate composed of pleomorphic CD3+ CD4+ cells and large clusters of CD30+ cells (Figures 5 and 6), with atypical mitoses and necrotic foci. Histiocytes and rare neutrophils were also identified. The diagnosis of lymphomatoid papulosis (LyP), subtype A, was established. No therapy was administered, and spontaneous remission was documented after 14 weeks, with only residual postinflammatory hyperpigmentation.

Lymphomatoid papulosis is a self-regressing, chronic disorder. It is clinically characterized by the eruption of erythematous, papulonecrotic, and nodular lesions, which may appear anywhere on the body surface. Histopathologically, LyP shows features resembling CD30-positive T-cell lymphoma. ${ }^{1-4}$ LyP is included in the spectrum of primary cutaneous CD30-positive T-cell lymphoproliferative disorders, according to the World Health Organization. ${ }^{3}$ It has a favorable prognosis, with a 10 -year survival rate close to $100 \%$. Nevertheless, the link with future onset of malignant lymphomas has been established, underscoring the need for regular long-term surveillance. ${ }^{5-7}$ LyP is rarely diagnosed in children, and its peak age of onset is around the fifth decade. ${ }^{1,6}$ According to a systematic review published in 2016, only 251 pediatric patients were reported with LyP, worldwide, ${ }^{1}$ with a mean age at diagnosis of $9.3 \pm 4.6$ years. The clinical characteristics of LyP in children do not seem to differ substantially from those in adults. ${ }^{7}$ Papular presentation (reported in $59 \%$ of the cases) is the most common, followed by predominance of nodular lesions in $31.5 \%$ of the patients. ${ }^{1}$ Ulceration and necrosis were observed in $13.5 \%$ and $7.2 \%$, respectively. ${ }^{1}$

Our patient is one of the youngest reported cases. ${ }^{1,2}$ His severe presentation, with sustained high fever and the emergence of multiple ulcerated nodules, raised the differential diagnosis of infectious etiologies such as ecthyma or ecthyma gangrenosum, as well as pityriasis lichenoides et varioliformis acuta (PLEVA). About $36 \%$ of the patients included in a pediatric case series of LyP had a previous, concomitant, or retrospective diagnosis of pityriasis lichenoides $(\mathrm{PL})$, with their lesions described as smaller and more numerous than those of LyP. Additionally, these lesions were not vesicular, pustular, or nodular. ${ }^{2}$ A rare, severe variant of PLEVA, febrile ulceronecrotic Mucha-Habermann disease (FUMHD), is characterized by a clinical picture similar to our patient's presentation, with sudden onset of ulceronecrotic skin lesions associated with high fever and systemic symptoms, commonly affecting children. ${ }^{8}$ However, compared to LyP, the cutaneous lesions of FUHMD tend to be more generalized and associated with mucosal involvement in $25 \%$ of the cases. Histopathology is distinctive showing a predominance of CD8+ T cells in the lymphocytic infiltrate; rarely, atypical lymphoid cells or CD30+ lymphoid cells, organized in a nonspecific pattern, may be seen in FUHMD skin biopsies. ${ }^{9}$ In the differential diagnosis of LyP, it is mandatory to exclude primary cutaneous CD30+ anaplastic large-cell lymphoma (PCALCL), which is an entity in the spectrum of the primary cutaneous CD30-positive lymphoproliferative disorders. Normally, PCALCL presents as a solitary nodule or tumor, although multiple lesions can be found. On immunohistochemistry, CD30 must be expressed by the majority (>75\%) of the neoplastic cells. ${ }^{4}$ It is not a self-limited disease, but requires treatment, which can be surgical resection, localized radiotherapy, or, in cases of extracutaneous dissemination, systemic chemotherapy/ immunotherapy. ${ }^{4}$

Histopathology is necessary to achieve a definite diagnosis of LyP. ${ }^{3,5}$ The recognition of the 6 different LyP subtypes ( $A$ to $F$ ) is important to avoid misdiagnosis, but has no therapeutic or prognostic implications. ${ }^{3}$ Similar to the adult paradigm, the most common histologic subtype reported in children is type $\mathrm{A}(79.1 \%),{ }^{1}$ also the type identified in our clinical case. The self-remitting course of LyP, usually within 12 weeks, ${ }^{2}$ was also observed in our patient, with only supportive treatment performed. There has been no evidence of relapse or recurrence in 6 months of follow-up.

While rare, it is important to consider LyP in the differential diagnosis of an ulcerated papulonodular eruption in infants. Because of the risk of subsequent systemic malignant lymphoma, the diagnosis of LyP in children raises important prognostic and management issues, with the need for close long-term monitoring.

\section{ORCID}

José Miguel Neves iD https://orcid.org/0000-0002-9014-2031

\section{REFERENCES}

1. Wieser I, Wohlmuth C, Nunez CA, Duvic M. Lymphomatoid papulosis in children and adolescents: a systematic review. Am J Clin Dermatol. 2016;17(4):319-327.

2. Miquel J, Fraitag S, Hamel-Teillac D, et al. Lymphomatoid papulosis in children: a series of 25 cases. Br J Dermatol. 2014;171(5):1138-1146.

3. Willemze R, Cerroni L, Jaffe ES, et al. The 2018 update of the WHOEORTC classification for primary cutaneous lymphomas. Blood. 2019;133(16):1703-1714.

4. Ceppi F, Pope E, Ngan B, Abla O. Primary cutaneous Iymphomas in children and adolescents francesco. Pediatr Blood Cancer. 2016;63(11):1886-1894.

5. Cordel N, Tressieres B, D'Incan M, et al. Frequency and risk factors for associated lymphomas in patients with lymphomatoid papulosis. Oncologist. 2016;21(1):76-83.

6. Wieser I, Oh CW, Talpur R, Duvic M. Lymphomatoid papulosis: treatment response and associated lymphomas in a study of 180 patients. J Am Acad Dermatol. 2016;74(1):59-67.

7. Nijsten T, Curiel-Lewandrowski C, Kadin ME. Lymphomatoid papulosis in children. Arch Dermatol. 2004;140(3):306-312.

8. Nofal A, Assaf M, Alakad R, Amer H, Nofal E, Yosef A. Febrile ulceronecrotic Mucha-Habermann disease: proposed diagnostic criteria and therapeutic evaluation. Int J Dermatol. 2016;55(7):729-738.

9. Borra T, Custrin A, Saggini A, et al. Pityriasis lichenoides, atypical pityriasis lichenoides, and related conditions. Am J Surg Pathol. 2018;42(8):1101-1112. 